\title{
Analisis Biplot terhadap Pemetaan Kebutuhan Guru SMP di Kabupaten Kepulauan Sangihe Berdasarkan Rasio Guru per Mata Pelajaran
}

\author{
Listiani Amare ${ }^{1}$, Jantjce D Prang ${ }^{2}$, Tohap Manurung ${ }^{3}$ \\ ${ }^{1}$ Program Studi Matematika, FMIPA, UNSRAT Manado, liztiani198@gmail.com \\ ${ }^{2}$ Program Studi Matematika, FMIPA, UNSRAT Manado, jdprang@yahoo.com \\ ${ }^{3}$ Program Studi Matematika, FMIPA, UNSRAT Manado, Krisston79@yahoo.com
}

\begin{abstract}
Abstrak
Penelitian ini bertujuan untuk mengaplikasikan analisis Biplot pada pemetaan kebutuhan guru Sekolah Menengah Pertama di Kabupaten Kepulauan Sangihe berdasarkan rasio guru per mata pelajaran. Penelitian dilakukan di Kabupaten Kepulauan Sangihe dengan menggunakan data primer yang diambil pada Dinas Pendidikan Pemuda dan Olahraga Kabupaten Kepulauan Sangihe dan SMP-SMP melalui kuisoner yang diisi oleh Kepala Sekolah bersama Kepala Tata Usaha sebanyak 10 Sekolah Menengah Pertama dari total populasi sebanyak 48. Analisis Biplot merupakan penyajian grafik dua dimensi yang menampilkan secara simultan objek pengamatan (SMP) dan peubah (rasio guru). Dengan menggunakan analisis biplot, hasil penelitian ini menunjukkan bahwa sekolah yang memiliki karakteristik kebutuhan guru yang hampir sama adalah SMP Advent Tahuna, SMP N 5 Tabukan Utara, SMP Muhammadiyah, SMP N 1 Tabukan Selatan Tengah, SMP N 2 Manganitu Selatan, dan SMP N 4 Tamako. Sekolah yang memiliki karakteristik ketersediaan guru yang sama adalah SMP N 5 Tabukan Utara, SMP Muhammadiyah, SMP N 1 Tabukan Selatan Tengah, SMP N 2 Manganitu Selatan Tengah, SMP N 4 Tamako, dan SMP Kristen Sawang Jauh.
\end{abstract}

Kata kunci : Analisis biplot, Rasio guru

\section{Biplot Analysis of the Mapping The Needs of Teacher in Junior High School in Sangihe Island Regency Based Teacher Ratio of Subjects}

\begin{abstract}
This study aims to apply Biplot analysis in mapping the needs of teacher in Junior in Sangihe Island Regency based teacher ratio of subjects. The study was conducted in the District of Sangihe using primary data taken at the Departement of Education, Youth and Sport Sangihe Island Regency and junior high schools trough a questionnaire filled out by Principal together with the Head of Administation of 10 Junior high school of the total population of 48. Analysis Biplot is presentation of two-dimensional graph that displays simultaneously the object of observation (SMP) and variable (teacher ratio). By using analysis biplot, the result of this study indicate that a school that has the characteristict of teacher demmand are almost the same is SMP Andent Tahuna, SMP N 5 Nort Tabukan, SMP Muhammadiyah, SMP N 1 Central South Tabukan, SMP N 2 South Manganitu, and SMP N 4 Tamako. School that have the same characteristict of teacher supply is SMP N 5 North Tabukan, SMP Muhammadiyah, SMP N 1 Central South Tabukan, SMP $N 2$ Central South Manganitu, SMP N 4 Tamako, and SMP Christian Sawang Away.
\end{abstract}

Keywords: Biplot analysis, Teacher ratio

\section{Pendahuluan}

Departemen Pendidikan dan Kebudayaan Nasional menunjukkan masih banyak guru yang mengajar tidak sesuai dengan latar belakang pendidikan, masih banyak sekolah yang kekurangan guru mata pelajaran tertentu, masih banyak penumpukkan guru pada sekolah tertentu dan masih banyak guru yang belum memenuhi kualifikasi pendidikan minimal. Sebagai tenaga yang professional, guru diharapkan tidak hanya memiliki kualifikasi akademik, namun juga harus memiliki kompetensi yang memenuhi persyaratan.

Undang-Undang Nomor 14 tahun 2005 tentang guru dan dosen menyatakan bahwa dalam melaksanakan tugas, guru memiliki kewajiban untuk melaksanakan kewajiban mengajar 24 jam tatap muka setiap minggu, sehingga dalam rangka membina dan mengembangkan profesi guru untuk menunjang kelancaran pelaksanaan pengelolaan ketenagaan guru, maka diperlukan perhatian khusus para pengelola pendidikan, terutama dalam pendataan, penyebaran, dan pemerataannya 
Juga perlu direncanakan pemenuhan kebutuhan guru, perbantuan guru ke sekolah swasta, pemindahan guru dan pemerataannya [1].

Tujuan penelitian ini adalah : mengaplikasikan analisi biplot terhadap pemetaan kebutuhan guru Sekolah Menengah Pertama di Kabupaten Kepulauan Sangihe berdasarkan rasio gurua per mata pelajaran.

\section{Kebutuhan guru}

Kebutuhan guru (teacher demand) adalah tuntutan pemakai jasa profesional guru untuk memberikan pelayanan pendidikan terhadap anak didik pada lembaga pendidikan pemakai jasa guru itu.. Pada komponen ini unsur-unsur penting yang perlu diperhatikan adalah guru untuk bidang apa, untuk jenis dan jenjang pendidikan yang mana, dan dengan kualifikasi apa.

Ketersediaan guru (teacher supply) adalah upaya profesional lembaga pendidikan guru untuk memenuhi tuntutan akan tenaga guru dari lembaga pemakai jasa guru. Pada komponen ini, unsur-unsur esensial yang perlu mendapat perhatian adalah: guru apa dan dengan kualifikasi tingkat mana yang perlu disiapkan, apakah guru cukup tersedia, program apa yang dapat memenuhi persyaratan kualitatif guru yang diperlukan, dan berapa jumlah guru yang perlu disiapkan.

Perhitungan rasio guru untuk kebutuhan guru SMP dapat dituliskan sebagai berikut:

$$
K G=\frac{\mathrm{JTM}}{24}=\frac{\left(M P 1 \times \sum K 1\right)+\left(M P 2 \times \sum K 2\right)+\left(M P 3 X \sum K 3\right)}{24}
$$

Keterangan:

$\mathrm{KG}=$ kebutuhan guru

JTM = jumlah jam tatap muka per jenis guru per minggu

$\mathrm{MP}=$ alokasi jam mata pelajaran per minggu

$\sum \mathrm{K}=$ jumlah kelas/rombongan belajar

24 = wajib mengajar per minggu, digunakan angka 24

$1,2,3$ = tingkat 1,2 dan 3

Perhitungan rasio guru untuk ketersediaan guru SMP dapat dituliskan sebagai berikut:

$$
K T G=\frac{\mathrm{TJG}}{\mathrm{JTM}}=\frac{T J G}{\left(M P 1 X \sum K 1\right)+\left(M P 2 X \sum K 2\right)+\left(M P 3 X \sum K 3\right)}
$$

Keterangan:

$\mathrm{KTG}=$ ketersediaan guru

TJG = total jumlah guru yang tersedia per mata pelajaran

JTM $=$ jumlah tatap muka per jenis guru per minggu

MP = alokasi jam mata pelajaran per minggu

$\sum \mathrm{K}=$ jumlah kelas/rombongan belajar

$1,2,3=$ tingkat 1,2 dan 3 [2].

\section{Analisis Biplot}

Analisis biplot adalah suatu metode multivariat yang menggunakan baris dan kolom dalam suatu grafik. Metode ini digunakan untuk menampilkan objek dari variable-variabel di grafik yang sama dengan menumpang tindihkan antara plot variabel-variabel dengan objek yang diteliti. Biplot merupakan teknik statistik deskriptif dimensi ganda yang dapat menyajikan secara simultan segugus objek pengamatan dan peubah dalam suatu grafik pada suatu bidang datar sehingga ciriciri peubah dan objek pengamatan serta posisi relatif antara objek pengamatan dengan peubah dapat dianalisis [3].

Biplot dikembangkan atas dasar penguraian nilai singular (Singular Value Decomposition, $S V D)$. Dalam hal ini SVD membantu untuk memahami struktur data matriks secara lebih baik. Suatu matriks $X$ berpangkat $r$ berukuran (nxp) yang berisi $n$ pengamatan dan $p$ peubah dikoreksi terhadap nilai rataannya, maka matriks tersebut dapat dituliskan menjadi:

$$
X=U L A^{\prime}
$$

Dengan matriks $U$ dan $A$ masing-masing berukuran (n $\mathrm{x}$ r) dan (p x r) sehingga $U^{\prime} U=A^{\prime} A=I$. Jika $\lambda i$ adalah akar ciri dari matriks $X^{\prime} X$, maka $L$ adalah matriks diagonal berukuran $\left(\begin{array}{lll}r & x & r\end{array}\right)$ dengan unsur-unsur diagonal adalah akar kuadrat dari akar ciri $X^{\prime} X$ 
sehingga $\sqrt{\lambda_{1}} \geq \sqrt{\lambda_{2}} \geq \cdots \geq \sqrt{\lambda_{r}}$. Unsur-unsur diagonal dari matriks $L$ disebut nilai matriks singular matriks $X$. Kolom-kolom matriks $U$ terdiri dari $r$ vektor ciri dari matriks $X^{\prime} X$. Kolom-kolom matriks $U$ disebut vektor singular kolom matriks $X$ dalam ruang berdimensi $n$. Kolom-kolom matriks $A$ terdiri dari $\mathrm{r}$ vektor ciri dari matriks $X^{\prime} X$ yang berpadanan dengan akar ciri $\lambda$. Kolom-kolom matriks $A$ disebut vektor singular baris matriks $X$ dalam ruang berdimensi $p$. Dengan penjabaran persamaan:

$$
X=U L A^{\prime}=U L^{\alpha} L^{1-}{ }^{\alpha} A^{\prime}
$$

dengan pendefinisian $G=U L^{\alpha}$ dan $H=A L^{1-\alpha}$, Untuk $0 \leq \alpha \leq 1$ persamaan (4) dapat ditulis:

$$
X=G_{(n x r)} H_{(r x p)}^{\prime}
$$

Maka unsur ke-( $i j)$ matriks $X$ dapat ditulis sebagai:

$$
X_{i j}=g_{i} h_{j}
$$

dimana $i=1,2,3, \ldots, n$ dan $j=1,2,3, \ldots, p$.

Jika $X$ berpangkat dua, maka vektor baris $g_{i}$ dan vektor kolom $\mathrm{h}_{\mathrm{j}}$ dapat digambarkan dalam ruang berdimensi dua. Sedangkan matriks $X$ yang berpangkat lebih dari dua dapat didekati dengan matriks berpangkat dua, sehingga persamaan (6) dapat ditulis menjadi:

$$
{ }_{2} X_{i j}=g_{i} * h_{j} *
$$

dengan masing-masing $g_{i} *$ dan $h_{j}^{*}$ mengandung 2 unsur pertama vektor $g_{i}$ dan $h_{j}$ [4].

Dalam pendeskripsian biplot nilai skalar $\alpha$ yang muncul pada pendefinisian $F$ dan $G$ dapat mengambil nilai sembarang antara 0 dan $1(0 \leq \alpha \leq 1)$.

Jika $\alpha=0$ maka $F=U$ dan $G=A L$, sehingga: $\quad X^{\prime} X=G G^{\prime}$ Jika $\alpha=1$ maka $F=U L$ dan $G=A$, sehingga: $\quad X^{\prime} X=F F^{\prime}$ Jika $\alpha=0,5$ maka $F=U L^{1 / 2}$ dan $G=L^{1 / 2} A$, sehingga: $X=U L A^{\prime}$

Biplot pada nilai $\alpha=0,5$ dapat digunakan sebagai pilihan untuk menggambarkan tebaran gabungan vektor-vektor objek dan peubah karena menyatakan bahwa hasil kali objek dan peubah sama dengan unsur-unsur matriks $X$ [5].

Terdapat 4 hal penting yang bisa diperoleh dari tampilan biplot, yaitu:

1. Kedekatan antar objek yang diamati, bahwa dua objek yang memiliki karakteristik sama akan digambarkan sebagai dua titik dengan posisi yang berdekatan.

2. Keragaman peubah. Dalam biplot, peubah yang mempunyai nilai keragaman yang kecil digambarkan sebagai vektor pendek sedangkan peubah dengan nilai keragaman yang besar digambarkan sebagai vektor yang panjang.

3. Korelasi antar peubah. Pada biplot, peubah akan digambarkan sebagai garis berarah. Dua peubah yang memiliki nilai korelasi positif akan digambarkan sebagai dua buah vektor dengan arah yang sama atau membentuk sudut sempit. Sementara itu, dua peubah yang memiliki nilai korelasi negatif akan digambarkan dalam bentuk dua vektor dengan arah yang berlawanan atau membentuk sudut lebar (tumpul). Sedangkan dua peubah yang tidak berkorelasi akan digambarkan dalam bentuk dua vektor dengan sudut yang mendekati $90^{\circ}$ (siku-siku).

4. Nilai peubah pada suatu objek, dalam informasi ini bisa digunakan untuk melihat keunggulan dari setiap objek. Objek yang terletak searah dengan arah vektor peubah dikatakan bahwa objek tersebut mempunyai nilai diatas rata-rata. Namun jika objek terletak berlawanan dengan arah dari vektor peubah tersebut, maka objek tersebut memiliki nilai di bawah rata-rata. Sedangkan objek yang hampir berada ditengah-tengah berarti objek tersebut memiliki nilai dekat dengan rata-rata [6].

\section{Metodologi Penelitian}

\subsection{Populasi dan sampel}

Dari 54 Sekolah Menengah pertama yang ada di Kabupaten Kepulauan Sangihe yang dijadikan populasi penelitian adalah 48 sekolah. Sekolah yang tidak dijadikan populasi adalah sekolah yang berada di luar pulau besar. Pengambilan jumlah sampel yang digunakan yaitu dengan simple random sampling (sampling acak sederhana). Teknik menentukan ukuran sampel dari populasi dalam penelitian ini yaitu Teknik Slovin : 


$$
\mathrm{n}=\frac{N}{N \cdot e^{2}+1}
$$

dimana: $\mathrm{n}=$ Jumlah sampel

$\mathrm{N}=$ Jumlah populasi

$\mathrm{e}^{2}=$ Presisi yang ditetapkan (10\%) [7].

$\mathrm{n}=\frac{48}{5.8}=8.27=8$

Besarnya sampel yang diperoleh dari persamaan (11) adalah 8 Sekolah, namun untuk hasil yang lebih baik sampel diambil lebih dari 8, jadi dalam penelitian ini akan diambil 10 sekolah yang akan dijadikan sampel.

\subsection{Objek Penelitian}

Sekolah Menengah Pertama yang dijadikan objek penelitian adalah sebagai berikut:

1.SMP N 3 Tahuna (S1)

2.SMP Advent Tahuna (S2)

3.SMP N 5 Tabukan Utara (S3)

4.SMP Muhammadiyah (S4)

5.SMP N 1 Tabukan Selatan Tengah (S5)
6. SMP Kristen Bellae (S6)

7.SMP N 2 Manganitu Selatan (S7)

8. SMP N 4 Tamako (S8)

9. SMP N 2 Tamako (S9)

10. SMP Kristen Sawang Jauh (S10)

\subsection{Waktu dan Tempat penelitian} Sangihe.

Penilitian ini dilakukan pada bulan Oktober - November 2015 di Kabupaten Kepulauan

\subsection{Peubah Penelitian}

Mata pelajaran yang akan dijadikan sebagai peubah dalam penelitian ini disajikan seperti pada tabel 1 .

Tabel 1. Peubah penelitian

\begin{tabular}{|c|l|}
\hline Kode & \multicolumn{1}{|c|}{ Nama Peubah } \\
\hline $\mathrm{X} 1$ & Rasio Guru Bahasa Indonesia \\
\hline $\mathrm{X} 2$ & Rasio Guru Penjas Orkes \\
\hline $\mathrm{X} 3$ & Rasio Guru Pendidikan Agama \\
\hline $\mathrm{X} 4$ & Rasio Guru Pendidikan Kewarganegaraan \\
\hline $\mathrm{X} 5$ & Rasio Guru Seni Budaya \\
\hline $\mathrm{X} 6$ & Rasio Guru Bahasa Inggris \\
\hline $\mathrm{X} 7$ & Rasio Guru Matematika \\
\hline $\mathrm{X} 8$ & Rasio Guru IPS Terpadu \\
\hline $\mathrm{X} 9$ & Rasio Guru IPA Terpadu \\
\hline
\end{tabular}

\subsection{Metode Analisis Data}

Tahap-tahap yang dilakukan pada analisis biplot adalah sebagai berikut:

1. Melakukan perhitungan rasio kebutuhan guru per mata pelajaran

2. Melakukan perhitungan rasio ketersediaan guru per matapelajaran

3. Membuat matriks data $X$ dari nilai rasio guru yang di peroleh

4. Standarisasi matriks $X$

5. Penguraian matriks $X$ yang telah distandarisasi dengan SVD

6. Perhitungan matriks $\mathrm{H}=\mathrm{AL}$ dan $\mathrm{G}=\mathrm{UL}$

7. Membuat plot matriks $\mathrm{G}$ dan $\mathrm{H}$ secara tumpang tindih.

\section{Hasil dan Pembahasan}

\subsection{Rasio Guru}

Perhitungan Rasio untuk kebutuhan guru dapat dihitung dengan menggunakan persamaan (1), dan perhitungan rasio untuk ketersediaan guru dapat dihitung dengan menggunakan persamaan (2). 
5.1.1. Rasio Kebutuhan Guru

Hasil perhitungan rasio kebutuhan guru per mata pelajaran disajikan pada tabel 2 .

Tabel 2. Rasio kebutuhan guru

\begin{tabular}{|c|c|c|c|c|c|c|c|c|c|}
\hline KODE & $\mathrm{X} 1$ & $\mathrm{X} 2$ & $\mathrm{X} 3$ & $\mathrm{X} 4$ & $\mathrm{X} 5$ & $\mathrm{X} 6$ & $\mathrm{X} 7$ & $\mathrm{X} 8$ & $\mathrm{X} 9$ \\
\hline S1 & 1.5 & 1 & 0.75 & 0.75 & 0.75 & 1.5 & 1.5 & 1.5 & 1.5 \\
\hline S2 & 0.5 & 0.25 & 0.375 & 0.25 & 0.25 & 0.5 & 0.5 & 0.5 & 0.5 \\
\hline S3 & 0.5 & 0.25 & 0.25 & 0.25 & 0.25 & 0.5 & 0.5 & 0.5 & 0.5 \\
\hline S4 & 0.5 & 0.25 & 0.25 & 0.25 & 0.25 & 0.5 & 0.5 & 0.5 & 0.5 \\
\hline S5 & 0.5 & 0.25 & 0.25 & 0.25 & 0.25 & 0.5 & 0.5 & 0.67 & 0.5 \\
\hline S6 & 0.5 & 0.375 & 0.25 & 0.25 & 0.375 & 0.5 & 0.5 & 0.5 & 0.5 \\
\hline S7 & 0.5 & 0.25 & 0.25 & 0.25 & 0.25 & 0.5 & 0.5 & 0.5 & 0.5 \\
\hline S8 & 0.5 & 0.25 & 0.25 & 0.25 & 0.25 & 0.5 & 0.5 & 0.5 & 0.5 \\
\hline S9 & 0.67 & 0.33 & 0.33 & 0.33 & 0.33 & 0.67 & 0.67 & 0.67 & 0.67 \\
\hline S10 & 0.625 & 0.25 & 0.25 & 0.25 & 0.25 & 0.5 & 0.625 & 0.5 & 0.75 \\
\hline
\end{tabular}

\subsubsection{Rasio Ketersediaan Guru}

Hasil perhitungan rasio ketersediaan guru per mata pelajaran disajikan pada tabel 3.

Tabel 3. Rasio ketersediaan guru

\begin{tabular}{|c|c|c|c|c|c|c|c|c|c|}
\hline KODE & $\mathrm{X} 1$ & $\mathrm{X} 2$ & $\mathrm{X} 3$ & $\mathrm{X} 4$ & $\mathrm{X} 5$ & $\mathrm{X} 6$ & $\mathrm{X} 7$ & $\mathrm{X} 8$ & $\mathrm{X} 9$ \\
\hline S1 & 0.028 & 0.042 & 0.056 & 0.111 & 0.056 & 0.056 & 0.028 & 0.083 & 0.056 \\
\hline S2 & 0.083 & 0.167 & 0.222 & 0.167 & 0.167 & 0.083 & 0.167 & 0.167 & 0.167 \\
\hline S3 & 0.167 & 0.167 & 0.167 & 0.167 & 0.167 & 0.083 & 0.083 & 0.083 & 0.083 \\
\hline S4 & 0.083 & 0 & 0.167 & 0.167 & 0.167 & 0.083 & 0.083 & 0.167 & 0.083 \\
\hline S5 & 0.083 & 0.167 & 0.167 & 0.167 & 0.167 & 0.083 & 0.083 & 0.125 & 0.083 \\
\hline S6 & 0.083 & 0.111 & 0.167 & 0.167 & 0.111 & 0.167 & 0.083 & 0.083 & 0.083 \\
\hline S7 & 0.083 & 0.167 & 0.167 & 0.167 & 0.167 & 0.083 & 0.083 & 0.167 & 0.083 \\
\hline S8 & 0.083 & 0.167 & 0.167 & 0.167 & 0.167 & 0.083 & 0.083 & 0.083 & 0.083 \\
\hline S9 & 0.063 & 0.25 & 0.125 & 0.125 & 0.25 & 0.063 & 0.063 & 0.125 & 0.063 \\
\hline S10 & 0.067 & 0.167 & 0.333 & 0.167 & 0.167 & 0.083 & 0.067 & 0.083 & 0.111 \\
\hline
\end{tabular}

\subsection{Standarisasi Rasio Guru}

\subsubsection{Standarisasi Rasio Kebutuhan Guru}

Hasil standarisasi rasio kebutuhan guru disajikan pada tabel berikut:

Tabel 4. Hasil standarisasi kebutuhan guru

\begin{tabular}{|c|c|c|c|c|c|c|c|c|c|}
\hline KODE & $\mathrm{X} 1$ & $\mathrm{X} 2$ & $\mathrm{X} 3$ & $\mathrm{X} 4$ & $\mathrm{X} 5$ & $\mathrm{X} 6$ & $\mathrm{X} 7$ & $\mathrm{X} 8$ & $\mathrm{X} 9$ \\
\hline S1 & 2.32289 & 0.89136 & 0.88220 & -0.46413 & 0.78390 & 0.78082 & 2.32289 & 0.51751 & 0.87518 \\
\hline S2 & 0.49753 & 0.89136 & -0.40732 & 0.78532 & 0.78390 & 0.78082 & -0.41515 & -0.05390 & -0.30696 \\
\hline S3 & -0.41515 & 0.89136 & 0.88220 & 0.78532 & 0.78390 & 0.78082 & 0.49753 & 1.37463 & 0.87518 \\
\hline S4 & 0.49753 & -1.41487 & 0.88220 & 0.78532 & 0.78390 & 0.78082 & 0.49753 & -0.05390 & 0.87518 \\
\hline S5 & 0.49753 & 0.89136 & 0.88220 & 0.78532 & 0.78390 & 0.78082 & 0.49753 & -0.05390 & 0.87518 \\
\hline S6 & 0.49753 & 0.89136 & 0.88220 & 0.78532 & 0.78390 & -0.37504 & 0.49753 & 1.37463 & 0.87518 \\
\hline S7 & 0.49753 & 0.89136 & 0.88220 & 0.78532 & 0.78390 & 0.78082 & 0.49753 & -0.05390 & 0.87518 \\
\hline S8 & 0.49753 & 0.89136 & 0.88220 & 0.78532 & 0.78390 & 0.78082 & 0.49753 & 1.37463 & 0.87518 \\
\hline S9 & 0.49753 & -0.26176 & 0.88220 & 0.78532 & -0.46515 & 0.78082 & 0.49753 & -0.05390 & 0.87518 \\
\hline S10 & 0.49753 & 0.89136 & -0.40732 & 0.78532 & 0.78390 & 0.78082 & 0.49753 & 1.37463 & -0.30696 \\
\hline
\end{tabular}




\subsubsection{Standarisasi Rasio Ketersediaan Guru}

Hasil standarisasi rasio ketersediaan guru disajikan pada tabel berikut:

Tabel 5. Hasil standarisasi ketersediaan guru

\begin{tabular}{|c|c|c|c|c|c|c|c|c|c|}
\hline KODE & $\mathrm{X} 1$ & $\mathrm{X} 2$ & $\mathrm{X} 3$ & $\mathrm{X} 4$ & $\mathrm{X} 5$ & $\mathrm{X} 6$ & $\mathrm{X} 7$ & $\mathrm{X} 8$ & $\mathrm{X} 9$ \\
\hline S1 & -1.27671 & -1.31801 & -1.55241 & -1.43619 & -1.57430 & -1.40144 & -1.27671 & -1.24530 & -1.35671 \\
\hline S2 & -1.17632 & -1.02973 & -1.12429 & -1.29625 & -1.29701 & -1.33902 & -1.02299 & -1.00531 & -1.09427 \\
\hline S3 & -1.02299 & -1.02973 & -1.26613 & -1.29625 & -1.29701 & -1.33902 & -1.17632 & -1.24530 & -1.29287 \\
\hline S4 & -1.17632 & -1.41487 & -1.26613 & -1.29625 & -1.29701 & -1.33902 & -1.17632 & -1.00531 & -1.29287 \\
\hline S5 & -1.17632 & -1.02973 & -1.26613 & -1.29625 & -1.29701 & -1.33902 & -1.17632 & -1.12530 & -1.29287 \\
\hline S6 & -1.17632 & -1.15888 & -1.26613 & -1.29625 & -1.43691 & -1.14484 & -1.17632 & -1.24530 & -1.29287 \\
\hline S7 & -1.17632 & -1.02973 & -1.26613 & -1.29625 & -1.29701 & -1.33902 & -1.17632 & -1.00531 & -1.29287 \\
\hline S8 & -1.17632 & -1.02973 & -1.26613 & -1.29625 & -1.29701 & -1.33902 & -1.17632 & -1.24530 & -1.29287 \\
\hline S9 & -1.21283 & -0.83832 & -1.37445 & -1.40121 & -1.08967 & -1.38526 & -1.21283 & -1.12530 & -1.34016 \\
\hline S10 & -1.20553 & -1.02973 & -0.83801 & -1.29625 & -1.29701 & -1.33902 & -1.20553 & -1.24530 & -1.22667 \\
\hline
\end{tabular}

\subsection{Analisis Biplot}

\subsubsection{Analisis Biplot Kebutuhan Guru}

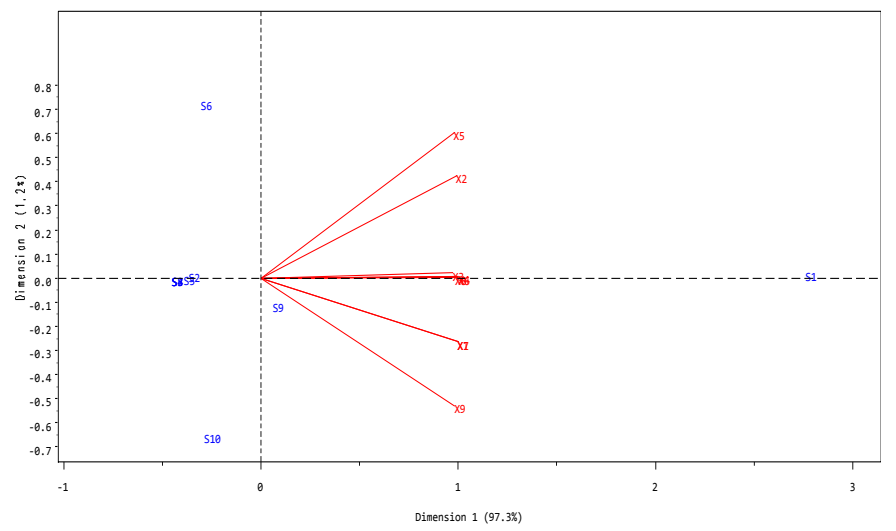

SMP Advent Tahuna (S2), SMP N 5 Tabukan Tengah (S3), SMP Muhammadiyah (S4), SMP N 1 Tabukan Selatan Tengah (S5), SMP N 2 Manganitu Selatan (S7), dan SMP N 4 Tamako (S8) memiliki karakteristik yang hampir sama untuk kebutuhan gurunya karena posisi ke enam sekolah tersebut saling berdekatan.

Keragaman peubah dapat dilihat pada gambar, semua peubah pada kebutuhan guru memiliki vektor yang hampir sama panjang. Hal ini menunjukkan bahwa presentase kebutuhan guru hampir sama untuk semua objek penelitian.

Peubah-peubah pada Kebutuhan guru Sekolah Menengah Pertama yang memiliki korelasi positif tinggi adalah guru Bahasa Indonesia (X1), guru Pendidikan Agama (X3), guru Pendidikan Kewarganegaraan (X4), guru Bahasa Inggris (X6), dan guru IPS Terpadu (S8).

\subsubsection{Analisis Biplot Ketersediaan Guru}

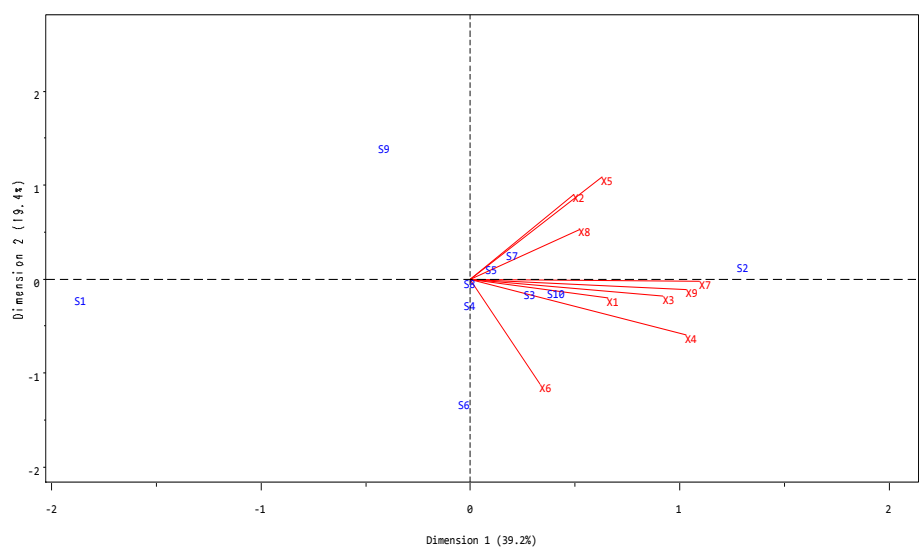

SMP N 5 Tabukan Utara (S3), SMP Muhammadiyah (S4), SMP N 1 Tabukan Selatan Tengah (S5), SMP N 2 Manganitu Selatan (S7), SMP N 4 Tamako (S8), dan SMP Kristen Sawang Jauh memiliki karakteristik yang hampir sama untuk ketersediaan guru karena posisi ke enam sekolah tersebut saling berdekatan.

Keragaman peubah dapat dilihat pada gambar, peubah yang memiliki vektor yang panjang berarti memiliki keragaman yang besar dan 
sebaliknya vektor yang pendek memiliki keragaman yang kecil. Rasio guru Matematika (X7) memiliki vektor terpanjang, jadi Rasio guru Matematika memiliki keragaman yang besar, artinya rasio guru Matematika untuk setiap objek penelitian hampir sama. Untuk rasio guru IPS Terpadu (X8) memiliki vektor terpendek, jadi rasio guru IPS Terpadu memiliki keragaman yang kecil, artinya rasio guru IPS Terpadu tidak sama untuk setiap objek penelitian.

Peubah-peubah pada Ketersediaan guru Sekolah Menengah Pertama yang mempunyai korelasi positif tinggi adalah guru Bahasa Indonesia (X1), guru Pendidikan Agama (X3), guru Pendidikan Kewarganegaraan (X4), guru Matematika (X7), dan guru IPA Terpadu (X9) karena peubah-peubah tersebut membentuk garis berarah dan membentuk sudut lancip. Ada juga peubah yang memiliki korelasi positif tinggi yaitu guru Penjas Orkes (X2) dan guru Seni Budaya (X5).

\section{Kesimpulan}

Berdasarkan hasil yang diperoleh dapat ditarik kesimpulan bahwa pada tampilan Biplot kebutuhan guru memberikan informasi yang diterangkan oleh dimensi 1 sebesar $97.3 \%$ dan dimensi 2 sebesar $1.2 \%$ sehingga total informasi yang kita peroleh sebesar 98.5\% dari keseluruhan informasi yang kita dapat secara manual. Peubah-peubah pada kebutuhan guru memiliki keragaman yang hampir sama karena panjang vektor dari peubah-peubah tersebut hampir sama. Sekolah Menengah Pertama yang memiliki korelasi positif tinggi adalah guru Bahasa Indonesia, guru Pendidikan Agama, guru Pendidikan Kewarganegaraan, guru Bahasa inggris, dan guru IPS Terpadu karena posisi dari ke-lima peubah tersebut berdekatan. Sekolah yang memiliki karakteristik kebutuhan guru yang hampir sama adalah SMP Advent Tahuna, SMP N 5 Tabukan Utara, SMP Muhammadiyah, SMP N 1 Tabukan Selatan Tengah, SMP N 2 Manganitu Selatan, dan SMP N 4 Tamako karena posisi dari ke-enam sekolah ini berdekatan.Pada tampilan Biplot ketersediaan guru memberikan informasi yang diterangkan oleh dimensi 1 sebesar $39.2 \%$ dan dimensi 2 sebesar $19.4 \%$ sehingga total informasi yang kita peroleh sebesar $58.6 \%$ dari keseluruhan informasi yang kita dapat secara manual. Keragaman terbesar dimiliki oleh guru Matematika sedangkan keragaman terkecil dimiliki oleh guru IPS Terpadu. Peubah-peubah pada Ketersediaan guru Sekolah Menengah Pertama yang mempunyai korelasi positif tinggi adalah guru Bahasa Indonesia, guru Pendidikan Agama, guru Pendidikan Kewarganegaraan, guru Matematika, dan guru IPA Terpadu karena peubah-peubah tersebut membentuk garis berarah dan membentuk sudut lancip. Ada juga peubah yang memiliki korelasi positif tinggi yaitu guru Penjas Orkes dan guru Seni Budaya. Sekolah yang memiliki karakteristik ketersediaan guru yang hampir sama adalah SMP N 5 Tabukan Utara, SMP Muhammadiyah, SMP N 1 Tabukan Selatan Tengah, SMP N 2 Manganitu Selatan Tengah, SMP N 4 Tamako, dan SMP Kristen Sawang Jauh karena posisi ke-enam sekolah tersebut berdekatan.

\section{Daftar Pustaka}

[1] Undang-Undang Republik Indonesia Nomor 14 Tahun 2005 Tentang Guru dan Dosen.

[2] Manap. S. 2009. Pemetaan Guru Berdasarkan Kebutuhan, Kualifikasi Pendidikan, dan Bidang Pengajaran Guru SMP di Kota Bengkulu. http://repository.unib.ac.id/8046/1/B2\%20Pemetaan\%20Guru\%20Ok.pdf. [21Oktober 2015]

[3] Gower. J. C and D. J Hand. 1996. Biplots (Monographs on Statistics and Applied Probability 54), First Edition, Chapman \& Hall.

[4] Jollife, I.T. 1986. Principle Component Analysis. Springer Verlag, New York

[5] Suranton. F. 2000. Metode Biplot dan Penggunaannya Pada Matriks Data, Depok, Universitas Indonesia.

[6] Mattjik. A.A, M. Sumertajaya, H. Wijayanto, Indahwati, A. Kurnia, B. Sartono. 2004. Modul Teori Pelatihan Analisis Multivariat. Departemen Statistika FMIPA IPB Bogor.

[7] Siregar. S. 2000. Statistika Deskriptif untuk Penelitian Dilengkapi Perhitungan Manual dan Aplikasi SAS Versi 17. PT Raja Grafindo Persada, Jakarta. 